\title{
Modified Kuppuswamy socioeconomic scale updated for the year 2020
}

\author{
Sheikh Mohd Saleem \\ Demonstrator, Dept. of Community Medicine, Government Medical College, Srinagar, J\&K, India \\ *Corresponding Author: Sheikh Mohd Saleem \\ Email: saleem.900@gmail.com
}

\begin{abstract}
Socioeconomic status (SES) is one among important indicators to evaluate the health status and nutritional status of a family. It is a position attained by any individual within a system of hierarchical social structure. Various attempts have been done in past by eminent scholars and medical scientists to formulate a group of composite indexes to determine SES of an individual or a family living in urban or rural areas. The scales have included various composite indexes to take into account details pertaining to an individual or any family. Among all the available SES, the most widely used and popular scale in our country is "Modified Kuppuswamy SES" which is mostly used for urban areas. In this paper, we have aimed at revising and providing an "Updated Modified Kuppuswamy SES" for the year 2020.The scale was initially developed by Kuppuswamy in the year 1976 including index parameters like education, occupation, and total income which was further modified in later years to include head of families educational status, occupational status and overall aggregate income of the whole family, pooled from all sources. The Kuppuswamy SES has included 3 parameters and each parameter is further classified into subgroups and scores have been allotted to each subgroup which have been defined later in this paper. The total score of Kuppuswamy SES ranges from 3-29 and it classifies families into 5 groups, "upper class, upper middle class, lower middle class, upper lower and lower socio-economic class." Due to limitations, the Kuppuswamy SES needs regular update for income levels which is based on changing CPI values which makes the scale vulnerable to fluctuations over time.
\end{abstract}

Keywords: Socioeconomic scale, Kuppuswamy scale, 2019 Update, Economic status.

\section{Introduction}

Socioeconomic status (SES) is one among important indicators to evaluate the health status and nutritional status of a family. In other words, the socio-economic status may be defined as "a position attained by any individual within a system of hierarchical social structure". ${ }^{1}$ SES has a major role to play in seeking health care services, accessibility issues, affordability costs, acceptance by beneficiaries and overall utilization of services by the people. ${ }^{2}$ In other words, the SES of any community has an influence on morbidity and mortality patterns in that particular community or geographic region. Mostly in scientific and social studies, many times determining patients SES sometimes help in arriving diagnosis of an individual or family. That is why SES is always a pre-requisite in history taking for health care individuals.

Various attempts have been done in past by eminent scholars and medical scientists to formulate a group of composite indexes to determine SES of an individual or a family living in urban or rural areas. The worth mentioning among those include, "Rahudkar scale in the year 1960, B. J Prasad scale in 1961, Udai Parikh scale in 1964, Jalota scale in the year 1970, Kuppuswamy scale in 1976 and Bhardwaj scale recently in the year $2001 .^{3}$

All the scales have included various composite indexes to take into account details pertaining to an individual or any family. Many scales have included scoring systems and later on classified individuals or families based on various categories. The scales have been formulated individually for urban as well as rural areas. The most common indexes taken into account include total income, educational status, and occupation. ${ }^{4}$ Among various scales for determining SES, the most widely and popularly used scales in India include "Updated Modified Kuppuswamy SES" which is mostly used for urban areas. ${ }^{5}$ However, due to the ongoing invasive economic growth and socioeconomic evolution over these years, the available SES have rendered inefficient in serving their usual purpose. For this reason, they need regular revisions over time to serve their purpose in ascertaining the SES of an individual or any family.

In this paper, we have aimed at revising and providing an "Updated Modified Kuppuswamy SES" scale for the year 2020 .

\section{Modified Kuppuswamy's SES scale}

This scale was devised by Kuppuswamy and is the most widely used scale for determining the socio-economic status of an individual or a family in urban areas. ${ }^{6}$ Initially the scale was formulated for determining SES of an individual but later on, it was modified to determine SES of a family rather than an individual. ${ }^{7}$ The scale was initially developed by Kuppuswamy in the year 1976 including index parameters like education, occupation, and total income which was further modified in later years to include head of families educational status, occupational status and overall aggregate income of the whole family, pooled from all sources. ${ }^{8}$ The Kuppuswamy SES has included 3 parameters and each parameter is further classified into subgroups and scores have been allotted to each subgroup which have been defined later in this paper. The total score of Kuppuswamy SES ranges from 3-29 and it classifies families into 5 groups, "upper class, upper middle class, lower middle class, upper lower and lower socio-economic class." The scale has been revised interminable over the past years because the parameter of overall income of the family from all the sources scale loses its pertinence following the devaluation in the worth of Indian rupee while the 
occupation of the head of family and education of the head of the family remains the same with time.

In order to carry out and perform the regular revision of the scale, the income scale in the Kuppuswamy SES is revised, "as per changes in the consumer price index (CPI) for industrial workers as projected by the central ministry of statistics and programme implementation on their website.9" The values of the CPI are "explicated in reference to a base year". As per the Labour Bureau, Government of India, "the current base year to be taken into account is 2012". ${ }^{10}$ An update of Kuppuswamy SES 2018 has used the latest base year for calculation purposes and has effectively determined correct income slabs. ${ }^{11}$ Here in this paper, we will use 2012 base year for calculating the income level of families to determine their socioeconomic status.

For calculation CPI, the current inflation rate of February 2020 i.e.: 6.58 has been taken into account. ${ }^{12}$ If we multiply the generated income scale values of the year 2012 with the conversion factor of 6.58 that will update the Kuppuswamy SES scale for February 2020. ${ }^{3}$ The inflation rate is calculated using the formula [(b-a/a) x 100], where ' $b$ ' is the CPI of current year and ' $a$ ' is the CPI of last year. ${ }^{13}$ Kindly refer to Tables I, II, III, and IV for "Updated Kuppuswamy's socioeconomic scale 2020".

Table 1: Occupation of the head of the family

\begin{tabular}{|l|l|c|}
\hline S. No. & Occupation of the Head & Score \\
\hline 1 & Legislators, Senior Officials \& Managers & 10 \\
\hline 2 & Professionals & 9 \\
\hline 3 & Technicians and Associate Professionals & 8 \\
\hline 4 & Clerks & 7 \\
\hline 5 & Skilled Workers and Shop \& Market Sales Workers & 6 \\
\hline 6 & Skilled Agricultural \& Fishery Workers & 5 \\
\hline 7 & Craft \& Related Trade Workers & 4 \\
\hline 8 & Plant \& Machine Operators and Assemblers & 3 \\
\hline 9 & Elementary Occupation & 2 \\
\hline 10 & Unemployed & 1 \\
\hline
\end{tabular}

Table 2: Education of the head of the family

\begin{tabular}{|l|l|c|}
\hline S. No. & Education of the Head & Score \\
\hline 1 & Profession or Honours & 7 \\
\hline 2 & Graduate & 6 \\
\hline 3 & Intermediate or diploma & 5 \\
\hline 4 & High school certificate & 4 \\
\hline 5 & Middle school certificate & 3 \\
\hline 6 & Primary school certificate & 2 \\
\hline 7 & Illiterate & 1 \\
\hline
\end{tabular}

Table 3: Total monthly income of the family

\begin{tabular}{|l|c|c|c|c|c|}
\hline S. No. & $\begin{array}{c}\text { Updated Monthly } \\
\text { Family Income in } \\
\text { Rupees } \\
\mathbf{( 2 0 1 2 )}\end{array}$ & $\begin{array}{c}\text { Updated Monthly } \\
\text { Family Income in } \\
\text { Rupees } \\
\mathbf{( 2 0 1 8 )}\end{array}$ & $\begin{array}{c}\text { Updated Monthly } \\
\text { Family Income in } \\
\text { Rupees } \\
(\mathbf{2 0 1 9 )}\end{array}$ & $\begin{array}{c}\text { Updated Monthly Family } \\
\text { Income in Rupees } \\
\mathbf{( 2 0 2 0 )}\end{array}$ & $\begin{array}{c}\geq 78,063 \\
\text { Score }\end{array}$ \\
\hline 1 & $\geq 30,375$ & $\geq 126,360$ & $39,033-78,062$ & 199,862 \\
\hline 2 & $15,188-30,374$ & $63,182-126,359$ & $29,200-39,032$ & $79,931-199,861$ \\
\hline 3 & $11,362-15,187$ & $47,266-63,181$ & $19,516-29,199$ & $4,756-99,930$ \\
\hline 4 & $7594-11,361$ & $31,591-47,265$ & $11,708-19,515$ & $29,962-74,755$ \\
\hline 6 & $4556-7593$ & $18,953-31,590$ & $3,908-11,707$ & 4 \\
\hline 7 & $1521-4555$ & $6327-18,952$ & $\leq 3,907$ & $10,002-29,972$ \\
\hline
\end{tabular}

Table 4: Kuppuswamy’s socio-economic status scale 2020

\begin{tabular}{|l|c|c|}
\hline S. No. & Score & Socioeconomic Class \\
\hline 1 & $26-29$ & Upper (I) \\
\hline 2 & $16-25$ & Upper Middle (II) \\
\hline 3 & $11-15$ & Lower Middle (III) \\
\hline 4 & $5-10$ & Upper Lower (IV) \\
\hline & $<5$ & Lower (V) \\
\hline
\end{tabular}


Though the Kuppuswamy SES is most widely and favorite scale used by social scientists, researchers in community-based and hospital-based studies. It too has some limitations which render the scales sensitivity in assessing the socioeconomic status of a family. Those include consideration of educational status and type of occupation of the head of the family for calculation of socioeconomic status which is completely unsuitable taking the current scenario into consideration. Moreover, the scale needs the regular update and is based on changing CPI values which makes the scale vulnerable to fluctuations in income levels.

\section{Source of Funding}

None.

\section{Conflict of Interest}

None.

\section{References}

1. Miner L, Bolding P, Hilbe J, Goldstein M, Hill T, Nisbet R, et al. Socioeconomic Status - an overview | ScienceDirect Topics [Internet]. 2015 [cited 2019 Mar 2]. Available from: https://www.sciencedirect.com/topics/medicine-anddentistry/socioeconomic-status

2. Institute of Medicine (US) Committee on Assuring the Health of the Public in the 21st Century. The Future of the Public's Health in the 21st Century. Washington (DC): National Academies Press (US); 2002. 5, The Health Care Delivery System. Available from: https://www.ncbi.nlm.nih.gov/books/NBK221227/

3. Singh T, Sharma S, Nagesh S. Socio-economic status scales updated for 2017. Int J Res Med Sci. 2017;5(7):3264.
4. Ramesh Masthi NR, Gangaboraiah, Kulkarni P. An exploratory study on socio economic status scales in a rural and urban setting. J Family Med Prim Care. 2013;2(1):69-73.

5. Bairwa M, Rajput M, Sachdeva S. Modified Kuppuswamy's Socioeconomic Scale: Social Researcher Should Include Updated Income Criteria, 2012. Indian J Community Med. 2013;38(3):185-6.

6. Shaikh Z, Pathak R. Revised Kuppuswamy and B G Prasad socio-economic scales for 2016. Int J Community Med Public Heal. 2017;4(4):997.

7. Modified Kuppuswamy Scale | PSM Made Easy [Internet]. [cited 2019 Mar 2]. Available from: http://www.ihatepsm.com/blog/modified-kuppuswamy-scale

8. Kuppuswamy B. Manual of socio-economic status scale (urban). Delhi; Manasyan;1981.

9. Ministry of Statistics and Program Implementation | Government Of India [Internet]. 2005 [cited 2019 Mar 2]. Available from: http://www.mospi.gov.in/

10. Labour Bureau Main [Internet]. [cited 2020 Mar 25]. Available from: http://labourbureau.gov.in/

11. Sheikh Mohd Saleem. Modified Kuppuswamy scale updated for year 2018. Indian J Res. 2018;7(3):6-7.

12. India Inflation Rate $\mid 2019$ | Data |Chart | Calendar | Forecast | News [Internet]. [cited 2020 Mar 25]. Available from: https://tradingeconomics.com/india/inflation-cpi

13. McMahon. How Do I Calculate the Inflation Rate? [Internet]. 2014 [cited 2020 Mar 25]. Available from: https://inflationdata.com/inflation/Inflation_Articles/CalculateI nflation. asp

How to cite this article: Saleem SM. Modified Kuppuswamy socioeconomic scale updated for the year 2020. Indian J Forensic Community Med. 2020;7(1):1-3. 